\title{
Incidence and Prevalence of Hypertension among Inmates in Three Correctional Facilities in Lusaka Province Zambia
}

\author{
Gift Himwaaba \\ Ph.D. in Public Health, Zambia Correctional Service, Lusaka Regional Medical \\ Coordinator, Zambia
}

\begin{abstract}
Hypertension is also known as high blood pressure is a global public health issue that has become very common worldwide and can lead to major health outcomes, such as myocardial infarction, stroke, renal failure, and ultimately death. The main objective of this study was to assess the incidences and the prevalence of hypertension among inmates. A correctional facility-based descriptive cross-sectional study was carried out to investigate the incidence and prevalence of hypertension among the inmates of Zambia's Lusaka-based three correctional facilities. A total of 311 inmates were included in this study of which 228 (73.3\%) were males and 83 (26.7\%) were females. Data is eternalized using the TATA version 15.0 software package. Descriptive statistics, Chi-square tests, fisher's exact test, and Logistic regression were used to examine, demographic characteristics, prevalence rate, correlation, risk factors, and association about hypertension. Among the participants, 54 (17.4\%) were found to be hypertensive. The median blood pressure for the hypertensive was 157.8/102 $\mathrm{mmHg}$ and the median blood pressure for non-hypertensive was 116/75 $\mathrm{mmHg}$. Incarceration variables correlated with hypertension were, duration of incarceration $p=0.0001$, reasons for detention $p=0.0001$, type of inmate $p=0.0150$. Old age, unemployed, major crimes, history of hypertension, smoking and body mass index were the risk factors for hypertension found among inmates. The prevalence of hypertension in the three correctional facilities in Zambia was found to be at 17.4\%, which was lower than the prevalence rate in most studies reviewed and even lower than the prevalence rate in the general population of some selected districts in Zambia.
\end{abstract}

Keywords: Correctional Facility, Hypertension, Incidence, Inmates, Lusaka, Prevalence.

\section{Introduction}

Hypertension is also known as high blood pressure is a global public health issue [1], which is becoming very common worldwide and can lead to major health outcomes, such as myocardial infarction, stroke, renal failure and ultimately death [2]. Furthermore, even slightly elevated blood pressure levels lead to increased risk of cardiovascular diseases, hence, it is one of the leading causes of the global burden of diseases [3], an estimated $57 \%$ and $24 \%$ of stroke and coronary artery disease-related deaths, respectively are due to hypertension [4]. As the global number of hypertensives was estimated at almost 1.13 billion with a prevalence rate of $30 \%$ to $45 \%$ range in adults, the global burden of morbidity and mortality related hypertension becomes one of the major public health concerns worldwide [4]. Effective blood pressure management has been shown to decrease the incidence of stroke, heart attack, and heart failure [5]. Primary hypertension is one of the cardiovascular diseases that is caused by different physiological and behavioural risk factors such as harmful use of alcohol, high body mass index, lead exposure, tobacco use, and a high-salt diet [6]. The World Health Organization reported high blood pressure to be more alarming in low- and middle-income 
countries [8]. Because of its asymptomatic nature, many people with the disease remain undiagnosed and untreated thus resulting in increased premature and sudden deaths due to direct or indirect complications [9]. The prevalence of hypertension in European countries ranges between $28 \%$ and $44 \%$, and the disease is highly correlated with stroke mortality and more modestly with cardiovascular disease [10]. Hypertension has increased from 594 in 1975 to 1.13 billion in 2015 [11].

Hypertension and other cardiovascular diseases rank among the leading causes of disability and deaths from non-communicable diseases in Africa [12]. In 2008 cardiovascular diseases caused $30 \%$ of all global deaths, of which over $80 \%$ were recorded from developing countries and in sub-Saharan countries, the prevalence of hypertension varies from $5 \%$ to $50 \%$ [13]. Several studies indicate that hypertension in sub-Saharan Africa is a widespread problem, and in some communities, it has been reported to be as high as $38 \%$ [14]. Currently, hypertension prevalence rates in some sub-Saharan African countries are among the highest in the world [15]. The relatively higher prevalence of hypertension in Africa has been linked to population growth and ageing, rising urbanization, mass migration from rural to urban areas, and increased uptake of western lifestyles including tobacco and alcohol consumption [13]. It has been suggested that the prevalence of cardiovascular disease and hypertension is increasing rapidly in Sub-Saharan Africa and the current prevalence in many developing countries, particularly in urban societies, is said to be already as high as those seen in developed countries [16].

In South Asia and sub-Saharan Africa, the World Health Organization estimates that the prevalence of hypertension is highest in the African region with about $46 \%$ of adults aged 25 years and older being hypertensive [17]. Hypertension is the leading preventable risk factor for premature death and disability worldwide [18]. Treatment and control of hypertension are critically important for the prevention of consequent cardiovascular and kidney disease [18]. Understanding hypertension prevalence and control among world regions is important for developing global strategies to better prevent and control hypertension through collaborative national and international efforts [18].

In Zambia, non-communicable diseases account for up to a quarter of all deaths, with about half of these due to cardiovascular diseases [19]. Hypertension has been recognized as a leading cause of morbidity and mortality in Zambia for a long time [20]. However, the proportion of people aware of having raised blood pressure remains low. In Zambia, studies of hypertension prevalence and risk factors have been sparse until more recently [21]. Oelke et al, 2015 found a prevalence of $32.8 \%$ hypertension in Zambian adults living in Mongu, the urban provincial capital of Western Province [22]. Slightly lower prevalence rates have been reported in rural Zambia. Mulenga et al 2013, reported a hypertension prevalence of $25.8 \%$ in Kaoma and 30.3\% in Kasama, two rural districts in Zambia [23]. Similarly, Yan et al, 2015 reported an age-standardized hypertension prevalence rate of $28 \%$ in adult Zambians ( $>25$ years) presenting to rural primary health clinics. The trends for population ageing and increased sedentary lifestyle, hypertension is expected to increase more [6]. This is highly undiagnosed as $78 \%$ of the subjects in Benin were unaware of their high blood pressure [6]. There are many behavioural risk factors for the development of hypertension these include Poor stress management [1]. These risk factors are highly influenced by people's working and living conditions [1]. Hypertension is a serious warning that significant lifestyle changes are required [1]. The condition can be a silent killer and everybody needs to know their blood pressure reading [1].

The correctional facility environment contributes to stress, which in turn leads to a variety of physical and psychological reactions 
such as depression, hopelessness, anxiety, nervousness, and hypertension, all factors associated with the pathogenesis of cardiovascular diseases [24]. Many unfavourable health outcomes, such as obesity and hypertension, result in part from poor health behaviour such as tobacco use and poor diet and these have been identified as the leading causes of death in the United States and research increasingly suggests that time behind bars exacerbates physical and mental health problems [25]. Obesity and overweight prevalence is socially patterned, with more prevalence among women, racial or ethnic minorities, and those with reduced socioeconomic status, there are contextual factors also affecting obesity risk, however, an omitted factor has been incarceration, particularly since it disproportionately affects minorities [26]. Incarceration may be an important influence on weight gain and have differential effects by race or ethnicity, education and imprisonment these are described as major primary stressors, involving major behavioural changes in a short period. Incarceration decreases social support and hampers social reintegration. Marriages fail and employment opportunities become hard to find for those with a criminal record. Stigma from a prison record can have social and psychological risks, as well as synergistic effects with cumulative disadvantage and secondary stressors.

Uncontrolled hypertension because of low health literacy may be a major problem in correctional institutions. Patients' knowledge about hypertension, may be a useful outcome measure, since self-management of the condition may be a vital part of treatment [27], Increased high blood pressure (HBP) knowledge has been associated with greater medication adherence, and better high blood pressure (HBP) control [28]. Most of the studies that have been done have shown that there is a high prevalence of hypertension among the incarcerated population. A study by Timnou et al, 2019 which was looking at the prevalence of hypertension and associated risk factors among a group of inmates in Yaoundé central prison, found a high prevalence of hypertension at $39.6 \%$ [29]. Another study by Gambhir et al, 2018 in Nepal at Jhumka regional prison in the eastern region of that country, found that half $50.7 \%$ had prehypertension and $13.1 \%$ and $9.0 \%$ of them had grade 1 and 2 hypertension respectively [30]. The main objective of this study was to assess the incidence and prevalence of hypertension among inmates in three correctional facilities namely, Lusaka Central, Lusaka Female and Mwembeshi Maximum in Lusaka province of Zambia. The specific objectives of this study were: to assess the incidence and prevalence of hypertension among inmates in correctional facilities, to establish the correlation of incarceration and prevalence of hypertension, to explore the underlying risk factors of the prevalence of hypertension among inmates, to ascertain the knowledge, attitudes, and perceptions of hypertension among inmates, hence find the way forward. The findings of this study are expected to contribute to primary prevention and intervention strategies in the treatment of hypertension in Zambia.

\section{Material and Methods}

\section{Ethical Statement}

This study was approved by the ministry of home affairs and correctional services management in Zambia, and written informed consent from each of the participants was obtained.

\section{Study Design and Setting}

A correctional facilities-based descriptive cross-sectional study from $1^{\text {st }}$ August 2020 to $30^{\text {th }}$ May 2021 was carried out to investigate the incidences and prevalence of hypertension among the inmates of Zambia's Lusaka based on three correctional facilities, namely Lusaka Central, Lusaka Female, and Mwembeshi Maximum. This comprises two male prisons (Lusaka Central Correctional Facility and Mwembeshi Maximum Correctional Facility) 
and one female prison (Lusaka Female Correctional Facility). Lusaka Central Correctional Facility is located about four kilometres from the central business district of Lusaka City, built-in 1949 with a holding capacity of 200 inmates and currently holds 1017 inmates. This prison holds all types of inmate's capital remands prohibited immigrants and convicted. Lusaka Female has a holding capacity of 100 inmates but currently holds 88 female inmates, it is located next to Lusaka central correctional facility, and this is the only female facility in Lusaka province holding a mixture of convicted, remands and prohibited immigrant inmates. Mwembeshi Maximum correctional facility was built in 2011 with a holding capacity of 600 and currently has 726 inmates, and it's a model prison, housing only long-term convicted inmates. This study included all inmates lodged at the time of the study. Correctional facilities are a good target for data collection because most participants are found in one place, making it more convenient and less costly. The research was carried out using data from the three correctional facilities, which comprised a clinic in each correctional facility.

\section{Variables and Measurement}

The participants in this study were randomly selected by allowing them to voluntarily come to the facility clinic and decide whether to participate in the study or not through consenting. To adhere to ethical protocol, the inclusion and exclusion criteria were observed during the participant recruitment process. We included all corporative, non-violent inmates aged 18 years and above, new and old inmates, including those with a clinical diagnosis of hypertension. Inmates below the age of 18 years, non-corporative, and those who did not provide full and valid consent were excluded. The sample size was determined by using Yamane's formula by assuming that $50 \%$ of the inmates will participate in the survey of the prevalence of hypertension in incarcerated to obtain a maximum sample size with a Precision level 95\% confidence interval and 5\% level of significance [31]. Therefore, the calculated sample size was 328 .

The collection of data was through questionnaires and structured interviews, physical examination, and controlled observation. Data collection was done at the facilities clinic by members of the research team, which also included the correctional Facilities, clinical staff. After giving informed consent, each inmate was interviewed face to face using standardized schedules. Regardless of symptoms, the blood pressure was checked and read by the clinicians and recorded. Records of responses were entered in the questionnaires and later in the computers. Full clinical examination was done such as vital signs (temperature, blood pressure, pulse rate, weight, and height), and self-reported health behaviour such as alcohol use, smoking, physical activity, and diet was done. Participants had the right to withdraw from participation without penalty, and they had the right to access individual research findings daily and upon study completion. In addition to routine screening, all inmates attending prison clinics during the study period were also screened for hypertension and were recorded as part of study participants upon consenting. Blood pressure abnormality was recorded in a standardized register. To address the objectives of this study, soliciting patients' information from three different sources was required. This research obtained information through A faceto-face interview with each participant by using a structured questionnaire to obtain demographic and social information. General screening and examination on participants to determine; the state of their blood pressure reading about hypertension, height, and weight.

The interviews were conducted on each participant regardless of their past state of health with a maximum duration of 5-10 minutes. Socio-demographic variables: sex, age, employment status, marital status, educational level, duration of incarceration, type of inmate, 
number of visits per month and reason for detention were collected. The questionnaire was ready and entered by the research team. Relevant general history such as the personal and family medical history of hypertension and information on hypertension knowledge levels was also collected.

Physical examinations were done using controlled measurements such as blood pressure machine, standiometer and weight scale and participant's blood pressure, body weight, and height, were obtained. Body weight was measured in kilograms using equinox personal weighing scale model EQ-BR-9201 made in India and height was measured in meters in standing position using a Telescopic Seca height Measuring Rod made in china. The blood pressure was measured using a citizen digital blood pressure measuring machine made by citizen systems of Japan. The participants sampling process is summarized in Figure 1 below

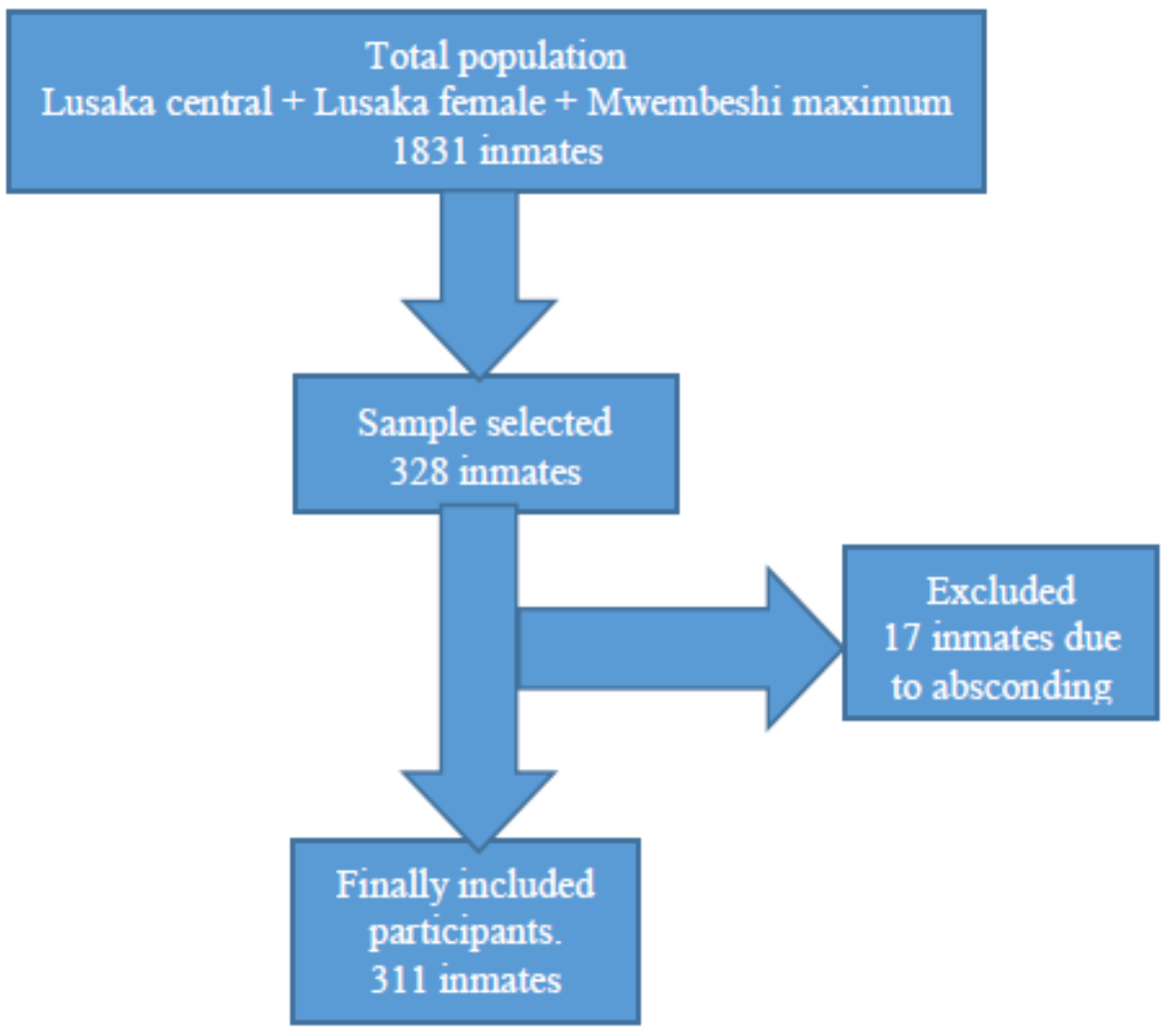

Figure 1. Participants Sampling Flow Chart

\section{Diagnostic Criteria Variables Defined}

Blood pressure was measured twice with intervals of five (5) minutes and repeated on two or more occasions to diagnose one as being hypertensive. All those with average blood pressure readings of systolic of $140 \mathrm{mmHg}$ and above and diastolic of $90 \mathrm{mmHg}$ and above were termed hypertensive and referred for further appropriate clinical management.
Age group ranges were grouped as follows 18 to 19,20 to 29,30 to 39,40 to 49 years range, 50 to 59 , and those with more than 60 years and above. Body mass index was also calculated using weight in kilograms divided by height in meters squared. Diagnostic criteria for body mass index were as follows, body mass index < 18.5 (underweight), body mass index of 18.5 24.9 (normal), body mass index BMI $25-29.9$ (overweight), and body mass index $\geq 30 \mathrm{~kg} / \mathrm{m}^{2}$ (obese). 
Marital status was defined as single for those who were not married, married for those who left their spouses home when they came to prison, divorced those who had divorced their spouses, and widowed those whose spouses had died. Educational level was defined as primary level, meaning from no formal education up to grade seven, secondary level meaning from grade eight to grade twelve, tertiary level meaning any college education after secondary school. Employment status was defined as employed, meaning came out of employment before detention, and unemployed meant had no formal employment before detention.

Duration of incarceration was defined as short duration of incarceration as $<5$ years, the average duration of incarceration as $5-9$ years, and long duration of incarceration as $\geq 10$ years. Reasons for detention was defined as minor crimes or misdemeanour (prohibited immigrant, assault, forgery, unlawful wounding, theft by servant, possession of government trophy) and major crimes or felonies (child assault, child battering, murder, human trafficking, abduction, aggravated robbery, and rape case) as per laws of Zambia. Type of inmate was defined as convicted (serving a sentence), remand (not convicted), prohibited immigrant (foreigners who enter the country illegally). The number of visits per month was defined as inexistent or no visit (0), Low number of visits (1 to 2), frequent number of visits (3 to 9), and very frequent (10 or more) in a month.

Smoking habits were defined as, smokers if one smokes cigarettes nearly every day or every day were considered smokers, non-smoker those who didn't smoke. Alcohol consumption was defined as taking alcohol if one used to drink alcohol before incarceration, no alcohol if you never used to drink before incarceration, taking into cognizant that the Zambian laws do not permit the inmates to take and drink alcohol in correctional facilities. Hypertension knowledge was defined according to the ability to answer correctly the twelve knowledge questions. Inadequate knowledge if answered less than 6 correctly, adequate knowledge if answered 6 to 9 of questions correctly, good knowledge if answered more than 9 correctly.

Sporting activities were defined as the ability of the service to provide sporting activities to inmates while in detention or any provisions for exercises such as sports, walking around, and whether. Eating habits were defined in terms of food provision to inmates or who provided them with food. In this area, correctional services seem to provide food to every inmate.

\section{Statistical Analysis}

Data were analyzed using the STATA version 15.0 software package. The first stage in the analysis focused on describing eligibility and the study population. Subsequently, the outcome of screening (physical examination, face-to-face interviews) was described. Descriptive statistics were used to summarize the demographic and social characteristics of participants. Chi-square tests were used to analyze the association of all variables with hypertension, and for frequencies, less than 5, fisher's exact test was used. Logistic regression was used to examine risk factors for hypertension. We calculated the odds for each parameter studied in inmates. A probability value $<0.05$ was be used to characterize statistically significant results. Using significant parameters, a multivariate analysis by logistic regression was made.

The core analysis focused on weighing the relationship of hypertension with incarceration in these prison populations. Participants were classified in different blood pressure categories (hypertensive and non-hypertensive) based on the World Health Organization (WHO) cut-off criteria. Thus, a participant was classified as being hypertensive if their average systolic blood pressure (SBP) was more or equal to 140 $\mathrm{mm} \mathrm{Hg}$, and/or their average diastolic blood pressure (DBP) was more or equal to $90 \mathrm{~mm} \mathrm{Hg}$, or if they reported of being on regular antihypertensive therapy but with uncontrolled readings. The prevalence of hypertension was calculated as the percentage of participants 
classified as being hypertensive. Body Mass Index (BMI) was computed by dividing the weight in kilograms by the height in meters squared and used to develop the categories of underweight (less or equal to 18.5), normal weight (18.5-24.9), overweight (25.0-29.9), and obese (30 or higher). In all cases, results from old and new cases were treated the same in terms of the hypertension case definition.

To establish the correlation of incarceration and prevalence of hypertension, bivariate analysis was used on incarceration variables (duration of incarceration, reasons for detention, type of inmate, and several visits). To explore the underlying risk factors of hypertension, multivariable logistic regression was used. We calculated the odds for each parameter studied in inmates having hypertension compared with those who do not have hypertension. To ascertain hypertension knowledge among participants, face-to-face interviews we conducted using a questionnaire that had 12 knowledge questions answered by participants.

\section{Results}

A total of 311 prisoners were included in this study, of which $228(73.3 \%)$ were males and 83 (26.7\%) were females (Table 1). The median age of all the participants was 37 years. In males, the median age was 39.5 years, and in females, the median age was 30 years (Table 2). The 20 to 29 age group were the most frequent participating age group with a total of 90 (28.9\%) participants for both sexes, followed by 30 to 39 age group with $78(25.1 \%)$ participants (Table 1$)$. Some of the prominent demographic and social characteristics according to categories about the number of participants in each category was that; non-smokers had the highest number of participants at $249(80.1 \%)$, short duration of incarceration had 231 (74\%) inmates, adequate knowledge was the next with $210(67.5 \%)$ inmates, none alcohol consumers were 209 (67.2\%), the convicted participants were 207 $(66.6 \%)$, the married were $178(57.2 \%)$, the normal weight category was 194 (62.4\%), secondary education level had 173 (55.6\%) participants, the unemployed had (192 (61.7\%) participants, those who had no visitors were 157 (50.5\%) (Table 1).

Among the participants, 54 (17.4\%) inmates were found to be hypertensive (Table 1). Hypertension was more prevalent in male participants $48(21.1 \%)$ than in female participants $6(7.2 \%)$ (Table 5). The median systolic blood pressure for the hypertensive was $157.8 \mathrm{mmHg}$, and the median systolic for nonhypertensive was $116 \mathrm{mmHg}$ (table 3). The median diastolic blood pressure for the hypertensive was $102.3 \mathrm{mmHg}$, and the median diastolic for non-hypertensive was $75 \mathrm{mmHg}$ (table3). In general, the median systolic blood pressure in males was $121.5 \mathrm{mmHg}$, and in females, it was $118 \mathrm{mmHg}$, median diastolic blood pressure in males was $76.8 \mathrm{mmHg}$ and was $78 \mathrm{mmHg}$ in females. The median body mass index in hypertensive was 22.9 and in nonhypertensive was 23.1 (Table 4). Blood pressure was seen to increase with the increase in age pvalue 0.0001 . The highest blood pressure was found in those aged $\geq 60$ at $43.2 \%$ (table 5). Many variables: $\operatorname{Sex} p=0.0040$, age $p=0.0001$, marital status $\mathrm{p}=0.0001$, duration of incarceration $\mathrm{p}=0.0001$, reasons for detention $\mathrm{p}$ $=0.0001$, type of inmate $\mathrm{p}=0.0150$, alcohol consumption $\mathrm{p}=0.0320$ and sports activities $\mathrm{p}=$ 0.0190 were associated with hypertension in bivariate analysis. 
Table 1. Demographic and Social Characteristics of the Participants

\begin{tabular}{|c|c|c|c|c|}
\hline Characteristic & Number & Percent & 95\% Conf. Interval & Characteristic \\
\hline \multicolumn{5}{|l|}{ Blood pressure status } \\
\hline Not Hypertensive & 257 & 82.6 & 78.0 & 86.5 \\
\hline Hypertensive & 54 & 17.4 & 13.5 & 22.0 \\
\hline \multicolumn{5}{|l|}{ Sex } \\
\hline Male & 228 & 73.3 & 68.1 & 78.0 \\
\hline Female & 83 & 26.7 & 22.0 & 31.9 \\
\hline \multicolumn{5}{|l|}{ Age Group } \\
\hline 19 years and below & 10 & 3.2 & 1.7 & 5.9 \\
\hline 20 to 29 years & 90 & 28.9 & 24.1 & 34.3 \\
\hline 30 to 39 years & 78 & 25.1 & 20.6 & 30.2 \\
\hline 40 to 49 years & 61 & 19.6 & 15.6 & 24.4 \\
\hline 50 to 59 years & 35 & 11.3 & 8.2 & 15.3 \\
\hline 60 years and above & 37 & 11.9 & 8.7 & 16.0 \\
\hline \multicolumn{5}{|l|}{ Education level } \\
\hline Primary & 106 & 34.1 & 29.0 & 39.6 \\
\hline Secondary & 173 & 55.6 & 50.0 & 61.1 \\
\hline Tertiary & 32 & 10.3 & 7.4 & 14.2 \\
\hline \multicolumn{5}{|l|}{ Marital Status } \\
\hline Single & 106 & 34.1 & 29.0 & 39.6 \\
\hline Married & 178 & 57.2 & 51.6 & 62.7 \\
\hline Divorced & 17 & 5.5 & 3.4 & 8.6 \\
\hline Widowed & 10 & 3.2 & 1.7 & 5.9 \\
\hline \multicolumn{5}{|l|}{ Employment Status } \\
\hline Employed & 119 & 38.3 & 33.0 & 43.8 \\
\hline Unemployed & 192 & 61.7 & 56.2 & 67.0 \\
\hline \multicolumn{5}{|c|}{ Duration of incarceration } \\
\hline Short & 231 & 74.3 & 69.1 & 78.9 \\
\hline Average & 59 & 19.0 & 15.0 & 23.7 \\
\hline Long & 21 & 6.8 & 4.4 & 10.2 \\
\hline \multicolumn{5}{|l|}{ Reason for Detention } \\
\hline Minor crimes & 127 & 40.8 & 35.5 & 46.4 \\
\hline Major crimes & 184 & 59.2 & 53.6 & 64.5 \\
\hline \multicolumn{5}{|c|}{ Family history of hypertension } \\
\hline No History & 170 & 54.7 & 49.1 & 60.1 \\
\hline History & 141 & 45.3 & 39.9 & 50.9 \\
\hline \multicolumn{5}{|l|}{ Type of inmate } \\
\hline Convicted & 207 & 66.6 & 61.1 & 71.6 \\
\hline Remand & 82 & 26.4 & 21.7 & 31.6 \\
\hline Prohibited Immigrant & 22 & 7.1 & 4.7 & 10.5 \\
\hline \multicolumn{5}{|l|}{ Number of visits } \\
\hline Inexistent & 157 & 50.5 & 44.9 & 56.0 \\
\hline Low & 94 & 30.2 & 25.4 & 35.6 \\
\hline
\end{tabular}




\begin{tabular}{|l|l|l|l|l|}
\hline Frequent & 50 & 16.1 & 12.4 & 20.6 \\
\hline Very Frequent & 10 & 3.2 & 1.7 & 5.9 \\
\hline Smoking habits & 249 & 80.1 & 75.2 & 84.2 \\
\hline Non-Smoker & 62 & 19.9 & 15.8 & 24.8 \\
\hline Smoker & \multicolumn{5}{l|}{} \\
\hline Alcohol Consumption & \multicolumn{5}{|l|}{} \\
\hline Non-Consumer & 209 & 67.2 & 61.8 & 72.2 \\
\hline Consumer & 102 & 32.8 & 27.8 & 38.2 \\
\hline Hypertension Knowledge & 30 & 9.6 & 6.8 & 13.5 \\
\hline Inadequate & 210 & 67.5 & 62.1 & 72.5 \\
\hline Adequate & 71 & 22.8 & 18.5 & 27.9 \\
\hline Very Adequate & 168 & 54.0 & 48.4 & 59.5 \\
\hline Sports activity & 143 & 46.0 & 40.5 & 51.6 \\
\hline Sports activity & 22 & 7.1 & 4.7 & 10.5 \\
\hline No Activity & 194 & 62.4 & 56.8 & 67.6 \\
\hline BMI Group & 71 & 22.8 & 18.5 & 27.9 \\
\hline BMI < 18.5 & 24 & 7.7 & 5.2 & 11.3 \\
\hline BMI 18.5 to 24.9 & &
\end{tabular}

Table 2. Median and Mean Age of the Participants in Years

\begin{tabular}{|l|l|l|l|l|l|}
\hline Age of Respondent & Number & Median & Mean & 1st Quartile & 3rd Quartile \\
\hline Blood Pressure Status \\
\hline Not Hypertensive & 257 & 33 & 36.3 & 26 & 43 \\
\hline Hypertensive & 54 & 51 & 53.1 & 44 & 63 \\
\hline Sex & 228 & 39.5 & 41.9 & 29 & 53 \\
\hline Male & 83 & 30 & 31.8 & 25 & 38 \\
\hline Female & 311 & 37 & 39.2 & 27 & 48 \\
\hline Overall &
\end{tabular}

Table 3. Median and Mean Systolic and Diastolic Blood Pressure $(\mathrm{mmHg})$ of the Participants

\begin{tabular}{|l|l|l|l|l|l|}
\hline Blood Pressure & & Median & Mean & & \\
\cline { 2 - 4 } Systolic BP & Number & Systolic & systolic & 1st Quartile & 3rd Quartile \\
\hline Blood Pressure Status \\
\hline Not Hypertensive & 257 & 116.0 & 117.5 & 109 & 124.5 \\
\hline Hypertensive & 54 & 157.8 & 161.9 & 148 & 173.5 \\
\hline Sex & 228 & 121.5 & 126.9 & 109.8 & 140.5 \\
\hline Male & 83 & 118.0 & 120.6 & 112 & 128 \\
\hline Female & Number & diastolic & diastolic & 1st Quartile & 3rd Quartile \\
\hline Diastolic BP & & & \\
\hline Blood Pressure Status & 75.0 & 75.1 & 68.0 & 82.5 \\
\hline Not Hypertensive & 257 & 102.3 & 103.1 & 95.5 & 105.5 \\
\hline Hypertensive & 54 &
\end{tabular}




\begin{tabular}{|l|l|l|l|l|l|}
\hline Male & 228 & 76.8 & 79.9 & 68.5 & 89.8 \\
\hline Female & 83 & 78.0 & 80.1 & 73 & 87 \\
\hline
\end{tabular}

Table 4. Median and Mean BMI of the Participants

\begin{tabular}{|l|l|l|l|l|l|}
\hline Body Mass Index & Number & Median & Mean & 1st Quartile & 3rd Quartile \\
\hline Blood Pressure Status \\
\hline Not Hypertensive & 257 & 23.1 & 23.6 & 20.7 & 25.7 \\
\hline Hypertensive & 54 & 22.9 & 23.9 & 21.3 & 25.1 \\
\hline Sex & 228 & 22.1 & 22.4 & 20.3 & 24.4 \\
\hline Male & 83 & 26.4 & 27.3 & 23.7 & 30.0 \\
\hline Female &
\end{tabular}

Many incarceration variables were found to be correlated with hypertension in bivariate analysis (table 5). Duration of incarceration $\mathrm{p}=$
0.0001 , reasons for detention $\mathrm{p}=0.0001$, and type of inmate $p=0.0150$, were found to be correlated with hypertension prevalence.

Table 5. Bivariate Analysis

\begin{tabular}{|c|c|c|c|c|c|}
\hline \multirow[b]{2}{*}{ Hypertension } & \multicolumn{2}{|c|}{ Not Hypertensive } & \multicolumn{2}{|c|}{ Hypertensive } & \multirow{3}{*}{$P$-value } \\
\hline & Number & Percent & Number & Percent & \\
\hline \multicolumn{5}{|l|}{ Sex } & \\
\hline Male & 180 & 79.0 & 48 & 21.1 & \\
\hline Female & 77 & 92.8 & 6 & 7.2 & \\
\hline \multicolumn{5}{|l|}{ Age Group } & \multirow{7}{*}{0.0001} \\
\hline 19 years and below & 10 & 100.0 & 0 & 0.0 & \\
\hline 20 to 29 years & 89 & 98.9 & 1 & 1.1 & \\
\hline 30 to 39 years & 70 & 89.7 & 8 & 10.3 & \\
\hline 40 to 49 years & 45 & 73.8 & 16 & 26.2 & \\
\hline 50 to 59 years & 22 & 62.9 & 13 & 37.1 & \\
\hline 60 years and above & 21 & 56.8 & 16 & 43.2 & \\
\hline \multicolumn{5}{|l|}{ Education level } & \multirow{4}{*}{0.1590} \\
\hline Primary & 84 & 79.3 & 22 & 20.8 & \\
\hline Secondary & 143 & 82.7 & 30 & 17.3 & \\
\hline Tertiary & 30 & 93.8 & 2 & 6.3 & \\
\hline \multicolumn{5}{|l|}{ Marital Status } & \multirow{5}{*}{0.0001} \\
\hline Single & 102 & 96.2 & 4 & 3.8 & \\
\hline Married & 138 & 77.5 & 40 & 22.5 & \\
\hline Divorced & 12 & 70.6 & 5 & 29.4 & \\
\hline Widowed & 5 & 50.0 & 5 & 50.0 & \\
\hline \multicolumn{5}{|l|}{ Employment Status } & \multirow{3}{*}{0.8380} \\
\hline Employed & 99 & 83.2 & 20 & 16.8 & \\
\hline Unemployed & 158 & 82.3 & 34 & 17.7 & \\
\hline \multicolumn{5}{|c|}{ Duration of incarcerations } & \multirow{4}{*}{0.0001} \\
\hline Short & 203 & 87.9 & 28 & 12.1 & \\
\hline Average & 40 & 67.8 & 19 & 32.2 & \\
\hline Long & 14 & 66.7 & 7 & 33.3 & \\
\hline
\end{tabular}




\begin{tabular}{|c|c|c|c|c|c|}
\hline \multicolumn{5}{|l|}{ Reason for Detention } & \multirow{3}{*}{0.0001} \\
\hline Minor crimes & 120 & 94.5 & 7 & 5.5 & \\
\hline Major crimes & 137 & 74.5 & 47 & 25.5 & \\
\hline \multicolumn{5}{|c|}{ Family history of hypertension } & \multirow{3}{*}{0.8760} \\
\hline No History & 141 & 82.9 & 29 & 17.1 & \\
\hline History & 116 & 82.3 & 25 & 17.7 & \\
\hline \multicolumn{5}{|l|}{ Type of inmate } & \multirow{4}{*}{0.0150} \\
\hline Convicted & 162 & 78.3 & 45 & 21.7 & \\
\hline Remand & 75 & 91.5 & 7 & 8.5 & \\
\hline Prohibited Immigrant & 20 & 90.9 & 2 & 9.1 & \\
\hline \multicolumn{5}{|l|}{ Number of visits } & \multirow{5}{*}{0.1350} \\
\hline Inexistent & 122 & 77.7 & 35 & 22.3 & \\
\hline Low & 81 & 86.2 & 13 & 13.8 & \\
\hline Frequent & 45 & 90.0 & 5 & 10.0 & \\
\hline Very Frequent & 9 & 90.0 & 1 & 10.0 & \\
\hline \multicolumn{5}{|l|}{ Smoking habits } & \multirow{3}{*}{0.3000} \\
\hline Non-Smoker & 203 & 81.5 & 46 & 18.5 & \\
\hline Smoker & 54 & 87.1 & 8 & 12.9 & \\
\hline \multicolumn{5}{|l|}{ Alcohol Consumption } & \multirow{3}{*}{0.0320} \\
\hline Non-Consumer & 166 & 79.4 & 43 & 20.6 & \\
\hline Consumer & 91 & 89.2 & 11 & 10.8 & \\
\hline \multicolumn{5}{|c|}{ Hypertension Knowledge } & \multirow{4}{*}{0.2060} \\
\hline Inadequate & 28 & 93.3 & 2 & 6.7 & \\
\hline Adequate & 173 & 82.4 & 37 & 17.6 & \\
\hline Very Adequate & 56 & 78.9 & 15 & 21.1 & \\
\hline \multicolumn{5}{|l|}{ Sports activity } & \multirow{3}{*}{0.0190} \\
\hline Sports activity & 131 & 78.0 & 37 & 22.0 & \\
\hline No Activity & 126 & 88.1 & 17 & 11.9 & \\
\hline \multicolumn{5}{|l|}{ BMI Group } & \multirow{5}{*}{0.4450} \\
\hline $\mathrm{BMI}<18.5$ & 21 & 95.5 & 1 & 4.6 & \\
\hline BMI 18.5 to 24.9 & 158 & 81.4 & 36 & 18.6 & \\
\hline BMI 25 to 29.9 & 58 & 81.7 & 13 & 18.3 & \\
\hline BMI 30 and above & 20 & 83.3 & 4 & 16.7 & \\
\hline
\end{tabular}

Risk factors associated with hypertension in the multivariable logistic regression analysis were old age, being male, unemployment, detention due to major crimes, family history of hypertension, smoking, and higher body mass index. In multivariable logistic regression analysis, old age $\mathrm{p}=0.0001$, major crimes $\mathrm{p}=$ 0.0370 , body mass index $p=0.0050$ were found to be the major risk factors for hypertension (Table 6).
Most of the participants, 210 (67.5\%), had adequate knowledge about hypertension, inadequate knowledge 30 (9.6\%), very adequate knowledge 71 (22.8) (Table 1). Of those with adequate knowledge, 37 (17.6\%) were hypertensive, and 173 (82.4\%) were not hypertensive, in the inadequate knowledge, 2 (6.7\%) were hypertensive, and 28 (93.3\%) were none hypertensive, in the very adequate knowledge 15 (21.1\%) and 56 (78.9\%) were non-hypertensive. 
Table 6. Multivariable Logistic Regression Analysis

\begin{tabular}{|c|c|c|c|}
\hline \multirow[b]{2}{*}{ Variable } & \multirow[b]{2}{*}{ OR } & Adjusted Estimates & \multirow[b]{2}{*}{ P-value } \\
\hline & & 95\% Conf. interval & \\
\hline \multicolumn{4}{|l|}{ Hypertension } \\
\hline Age of Participant & 1.0755 & 1.0452 & 1.1067 \\
\hline \multicolumn{4}{|l|}{ Sex } \\
\hline Male & Ref. & - & - \\
\hline Female & 0.2730 & 0.0646 & 1.1534 \\
\hline \multicolumn{4}{|l|}{ Education level } \\
\hline Primary & Ref. & - & - \\
\hline Secondary & 0.8391 & 0.3782 & 1.8617 \\
\hline Tertiary & 0.1015 & 0.0133 & 0.7726 \\
\hline \multicolumn{4}{|l|}{ Employment Status } \\
\hline Employed & Ref. & - & - \\
\hline Unemployed & 1.1291 & 0.5113 & 2.4933 \\
\hline \multicolumn{4}{|c|}{ Duration of incarceration } \\
\hline Short & Ref. & - & - \\
\hline Average & 0.9942 & 0.3978 & 2.4851 \\
\hline Long & 0.6077 & 0.1763 & 2.0951 \\
\hline \multicolumn{4}{|l|}{ Reason for Detention } \\
\hline Minor crimes & Ref. & - & - \\
\hline Major crimes & 3.3675 & 1.0787 & 10.5121 \\
\hline \multicolumn{4}{|c|}{ Family history of hypertension } \\
\hline No History & Ref. & - & - \\
\hline History & 1.3137 & 0.6208 & 2.7798 \\
\hline \multicolumn{4}{|l|}{ Type of inmate } \\
\hline Convicted & Ref. & - & - \\
\hline Remand & 0.5514 & 0.1951 & 1.5585 \\
\hline \multicolumn{4}{|l|}{ Number of visits } \\
\hline Inexistent & Ref. & - & - \\
\hline Low & 0.7900 & 0.3351 & 1.8624 \\
\hline Frequent & 0.7121 & 0.2056 & 2.4661 \\
\hline Very Frequent & 0.3689 & 0.0207 & 6.5885 \\
\hline \multicolumn{4}{|l|}{ Smoking habits } \\
\hline Non-Smoker & Ref. & - & - \\
\hline Smoker & 1.0593 & 0.3635 & 3.0870 \\
\hline \multicolumn{4}{|c|}{ Alcohol Consumption } \\
\hline Non-Consumer & Ref. & - & - \\
\hline Consumer & 0.9180 & 0.3805 & 2.2148 \\
\hline \multicolumn{4}{|l|}{ Sports activity } \\
\hline Sports activity & Ref. & - & - \\
\hline No Activity & 0.5297 & 0.2389 & 1.1742 \\
\hline BMI of Participant & 1.1698 & 1.0476 & 1.3062 \\
\hline Constant & 0.0002 & 0.0000 & 0.0052 \\
\hline
\end{tabular}




\section{Discussion}

This descriptive cross-sectional study was carried out to assess the incidence and prevalence of hypertension among inmates in three correctional facilities in Lusaka, Zambia. Currently, there is inadequate information in southern Africa regarding the topic in question. As such, most of the literature reviewed was from studies conducted in America, the Middle East, and the western central part of Africa and other countries. As such, this study represents the first published assessment of the prevalence of hypertension in Zambia's inmates' population.

Though many studies have been done on the prevalence of hypertension in the general population. Very few past studies have explored the prevalence of hypertension among the incarcerated population in Africa. Hypertension's incidences and prevalence among inmates particularly is still poorly known in southern Africa. Most of the studies done in western and some central African countries shows a high prevalence of hypertension in the incarcerated population. However, there is a scarcity of data in southern Africa and particularly in Zambia for its prevalence.

Several caveats need to be noted regarding the present study. Some of the caveats of this study are that our study sample size was small compared to most of the other studies reviewed on a similar subject. The other limitation is that the number of correctional facilities sampled was few. This study was also of a short period compared to other studies.

The prevalence of hypertension in the three correctional facilities in Lusaka province was $17.4 \%$, an indication of its dominance within the incarcerated population. The findings of this current study on the prevalence of hypertension in correctional facilities in Zambia are not consistent with the global burden which is at $30 \%$ to $45 \%$ range in adults, in Europe it is estimated at $28 \%$ to $44 \%$, in sub-Saharan Africa [14] found that hypertension is a widespread problem, and in some communities, it was reported to be as high as $38 \%$ and in Zambia [22] found hypertension prevalence at $32.8 \%$ in the general population of Mongu district of western province, reported hypertension prevalence in the general population of Kaoma and Kasama to be at $25.8 \%$ and $30.3 \%$ respectively [23]. On the contrary, Yaoundé prison prevalence of hypertension at $39.6 \%$ this study prevalence was much lower [29]. This study found that hypertension was more prevalent in male inmates at $21.1 \%$ than in female inmates $7.2 \%$ just like in other studies done in Zambia and other countries which has noted that the prevalence of hypertension to be more in men than females. The median systolic blood pressure for the hypertensive was 157.8 $\mathrm{mmHg}$ which was way above the definitive $\geq 140$ $\mathrm{mmHg}$ hypertension cut-off point and the median diastolic blood pressure for the hypertensives was $102.3 \mathrm{mmHg}$ way above the definitive $\geq 90 \mathrm{mmHg}$ cut off point for hypertension. Blood pressure was seen to increase with the increase in age p-value 0.0001 just like in the general population. The highest blood pressure was found in those aged $\geq 60$ at $43.2 \%$.

In this study, all the incarceration variables were found to be correlated with hypertension in bivariate analysis. It was interesting to note that in almost all the incarceration categories related variables, duration of incarceration $\mathrm{p}=0.0001$, reasons for detention $\mathrm{p}=0.0001$, and type of inmate $\mathrm{p}=0.0150$ were found to be correlated with hypertension prevalence among inmates. The mechanism by which incarceration may lead to hypertension has been noted in other studies as not known though some studies assume it may be due to the stress of being incarcerated. The results of this study in the multivariate analysis showed, like in other studies reviewed, that recent or short duration of incarceration increased hypertension among inmates. This may be due to; the stress of coping up with the new environment, loss of family ties, family members losing hope. Increased hypertension 
due to the long duration of incarceration $33.3 \%$ in the bivariate analysis may be a sign of lost hope of coming out of these correctional facilities. A possible explanation for the association between incarceration and the prevalence of hypertension includes a sedentary lifestyle, unhealthy diet, and high levels of stress. Incarceration may also be an independent risk factor for hypertension.

Most of the inmates are in a serious relationship when they leave for prison, which may be the reason why marital status $p=0.0001$ is an associated risk factor for hypertension [32]. This current study also found that, for every oneyear increase in age, the likelihood of being hypertensive increased $\mathrm{p}$-value $=0.0001$. This was an indication that the older an individual was, the higher the likelihood of being hypertensive, just like in the general population. The literature surrounding prisonization was pointed out in the literature review that it is very difficult for inmates to cope up and adapt to incarceration environment hence the likely link of the duration of incarceration, reasons for detention, type of inmate, and major crimes as risk factors for the incarcerated. The main risk factors that were found to be associated with hypertension were being male, older age above 40 years, primary education, divorced, widowed, the unemployed, average and $\log$ duration of incarceration, major crimes, history of hypertension in the family, convicted, and inexistent visitation.

In multivariable logistic regression analysis, the major risk factors for hypertension were old age $\mathrm{p}=0.0001$, major crimes $\mathrm{p}=0.0370$, body mass index $\mathrm{p}=0.0050$.

The results of this study show that, for every one-year increase in age, the likelihood of being hypertensive increased by a factor of 1.0755 , adjusting for other variables in the model, with 95\% CI $(1.0452,1.1067)$, p-value $=0.0001$. This was an indication that the older an individual was, the higher the likelihood of being hypertensive like in the general population.
Prior studies have noted the relationship between being male and the likelihood of being hypertensive is always positive. This study confirms this notion in that the odds of being hypertensive for female inmates were 0.2730 times less compared to male inmates, adjusting for other variables in the model, with 95\% CI $(0.0646,1.1534), p$-value $=0.0770$. This means that male inmates were more likely to be hypertensive compared to females, just like it has been known.

This also accords with the literature reviewed and this study which found that the likelihood of being hypertensive for inmates who had secondary level of education was reduced by 0.8391 times compared to those who had a primary level of education, adjusting for other variables in the model, with $95 \%$ CI $(0.3782$, 1.8617), $p$-value $=0.6660$. The likelihood of being hypertensive for inmates who had a Tertiary level of education was reduced by 0.1015 times compared to those who had a primary level of education. This means that those inmates who had lower levels of education were more likely to be hypertensive compared to those who had higher levels of education. The findings that the likelihood of being hypertensive for inmates who had a tertiary level of education is reduced compared to the primary level of education shows the importance of education which is greatly linked to hypertension knowledge. The findings in the unemployed category of participants were that the odds of being hypertensive for Unemployed inmates were 1.1291 times more compared to employed inmates, adjusting for other variables in the model, with $95 \%$ CI $(0.5113,2.4933)$, pvalue $=0.7640$. This means that employed inmates were less likely to be hypertensive compared to unemployed. This may be due to the stress put on them coupled with looking after their families without a steady income.

There are several possible explanations to multivariable logistic findings that the likelihood of being hypertensive for inmates who were incarcerated on average duration was reduced by 
0.9942 times compared to those who had a short duration of incarceration, adjusting for other variables in the model, with $95 \%$ CI $(0.3978$, 2.4851), $\mathrm{p}$-value $=0.990$. The likelihood of being hypertensive for inmates who were incarcerated for a long duration was reduced by 0.6077 times compared to those who had a short duration of incarceration. This means that those inmates who had a short duration of incarceration were more likely to be hypertensive compared to those who had a longer duration of incarceration. This may be due to trying to copy up with the lived reality of being in detention.

The odds of being hypertensive for inmates who were detained for major crimes were found to be 3.3675 times more compared to inmates who were detained for minor crimes, adjusting for other variables in the model, with $95 \% \mathrm{CI}$ (1.0787, 10.5121), $\mathrm{p}$-value $=0.0370$. This means that inmates who were detained for minor crimes were less likely to be hypertensive. The possible explanation for this may be that most of these inmates know that minor crimes attract less stiff sentencing compared to major crimes.

Another important finding was that the odds of being hypertensive for inmates who had a family history of hypertension were 1.3137 times more compared to inmates who had no family history of hypertension, adjusting for other variables in the model, with 95\% CI $(0.6208,2.7798)$, p-value $=0.4760$. This means that inmates who had no family history of hypertension were less likely to be hypertensive, just like in the general population where family history of hypertension is a major risk factor for hypertension.

It was also interesting to find that the likelihood of being hypertensive for inmates who were remand reduced by 0.5514 times compared to those who were convicted inmates, adjusting for other variables in the model, with $95 \%$ CI $(0.1951,1.5585)$, p-value $=0.2610$. The likelihood of being hypertensive for inmates who were prohibited immigrants was increased by 4.2464 times compared to those who were convicted inmates, and this may be because being incarcerated in a foreign country puts more stress on an individual.

The likelihood of being hypertensive for inmates who had low visits reduced by 0.7900 times compared to those who had no visits, adjusting for other variables in the model, with $95 \%$ CI $(0.3351,1.8624)$, p-value $=0.5900$. The likelihood of being hypertensive for inmates who had very frequent visits was reduced by 0.3689 times compared to those who had no visits. This means that the higher the number of visits an inmate had, the less likely they were to be hypertensive, being visited, or having relatives around you when in incarceration is consoling.

The odds of being hypertensive for inmates who had smoking habits were 1.0593 times more compared to inmates who had no smoking habits, adjusting for other variables in the model, with $95 \%$ CI $(0.3635,3.0870)$, p-value $=0.9160$. This means that inmates who were non-smokers were less likely to be hypertensive, just like in the general population, smoking is considered a risk factor as has been documented by most literature reviewed.

One unanticipated finding in multivariable logistic regression was that the odds of being hypertensive for inmates who consumed alcohol were 0.9180 times less compared to inmates who did not consume alcohol, adjusting for other variables in the model, with $95 \%$ CI $(0.3805$, $2.2148)$, $p$-value $=0.8490$. This was unexpected because in most cases and in general, alcohol is a known risk factor for hypertension, this finding may be due to that in Zambian correctional facilities, alcohol is a prohibited article in short, it's not allowed as such a variable was about before being incarcerated.

The other unexpected finding was the likelihood of being hypertensive for inmates who did not engage in sports activities was 0.5297 times less compared to inmates who engaged in sports activities, adjusting for other variables in the model, with $95 \%$ CI $(0.2389$, 1.1742), p-value $=0.1180$, which meant that inmates who engaged in sports activities were 
more likely to be hypertensive. The likely explanation for this was that sporting activities in these facilities are not regularly held.

For every unit increase in BMI, the odds of being hypertensive increased by a factor of 1.1698 , adjusting for with other variables in the model, with 95\% CI (1.0476, 1.3062), pvalue $=0.0050$. This indicated that the higher an individual's BMI was, the higher the likelihood of being hypertensive. This is just like in the general population, which links overweight to hypertension.

In previous studies such as by [33], it was acknowledged that knowledge was an important element of hypertension control. This may explain why hypertension was not as high as in other countries, because in this study, most of the participants, 210 (67.5\%), had adequate knowledge about hypertension. Furthermore, in this study, the prevalence of hypertension was not as high as in other countries probably it was because most of the inmates had adequate knowledge levels about hypertension within the inmate population. Prior studies have noted the importance of knowledge in managing hypertension, in this study, of the $67 \%$ who had adequate knowledge, only $17.6 \%$ were hypertensive, and $82.4 \%$ were not hypertensive, signifying significant connection and importance of knowledge as an outcome measure in hypertension.

The present findings seem to be consistent with other research, such as [26], which found high blood pressure knowledge as being associated with better high blood pressure control.

\section{Conclusion}

This study is the first of its kind to be done in Zambia concerning the prevalence of hypertension among inmates. The prevalence of hypertension in these Lusaka province-based correctional facilities was $17.4 \%$. The associated risk factors in these facilities were being male, older age above 40 years, primary education, divorced, widowed, the unemployed, average and $\log$ duration of incarceration, major crimes, history of hypertension in the family, convicted, and inexistent visitation. Despite hypertension not being as high as in other countries or in the general population, there is a need to put in place preventive measures in these facilities because the prevalence rate of this scourge among inmates is still high. Efforts should also be put in place to improve the early detection of hypertension, increase hypertension awareness in these incarcerated communities, and improve access to affordable healthcare for those with the condition. These findings are very important, such that now we know how prevalent high blood pressure is, among inmates as such it has given us the urgency to take corrective measures for its likely surge if overlooked for a longer period.

\section{Acknowledgements}

I would like to take this opportunity to thank the ministry of home affairs and the Zambia correctional service for allowing me to do this study in Lusaka province-based three correctional facilities. I would also like to thank Dr. Allan Zulu for his valuable input in this project. Finally, I must express my very profound gratitude to my family for all the support.

\section{Conflict of Interest}

Himwaaba Gift declares no conflict of interest. 


\section{References}

[1] World health organization. (2013). World health organization. A global brief on hypertension. Silent killer, Global Public Health Crisis. WHO/DCO/WHD/2013.2 www.int.who. communications@who.int.

[2] Khajedaluee, M., Hassannia, T., Rezaee, A., Ziadi, M., Dadgarmoghaddam, M. (2016). The prevalence of hypertension and its relationship with demographic factors, biochemical, and anthropometric indicators: A population-based study. Arya atherosclerosis, 12(6), 259-265. www.mui.ac.ir.

[3] Lacruz, M. E., Kluttig, A., Hartwig, S., Lo "er, M., Tiller, D., Greiser, K. H., Werdan, K., Haerting, J. (2015). Prevalence and Incidence of Hypertension in the General Adult Population Results of the CarlaCohort Study. Ph.D. ISSN: 0025-7974 Volume 94, Number 22, Doi: 10.1097/MD.0000000000000952. June 2015 www.md-journal.com.

[4] Ramakrishnan, S., Zachariah, G., Gupta, K., Rao, J. S., Mohanan, P. P... (2019). Prevalence of hypertension among Indian adults: Results from the great India blood pressure survey. Indian Heart Journal. 2019 Jul-Aug; 71(4):309-313. Doi: 10.1016/j.ihj.2019.09.012 [40].

[5] Desormais, I., Amidou, S. A., Houehanou, Y. C., Houinato, S. D., Gbagouidi, G. N., Pierre Marie Preux, P. M., Aboyans, V., Lacroix, P. (2019). The Prevalence, Awareness, Management and control of Hypertension in Men and Women in Benin, West Africa. https://doi.org/10.1186/s12872-019-01273-7. BMC.

[6] Fryar, C. D., Ostchega, Y., Hales, C. M., M.D., Zhang, G., Kruszon-Moran, D. (2017). Hypertension Prevalence and Control among Adults: The United States, 2015-2016 NCHS.

[7] Meiqari, L., Essink, D., Wright, P., Scheele, F. (2019). Prevalence of Hypertension in Vietnam: A Systematic Review and Meta-Analysis. Asia Pacific Journal of Public Health, Vol. 31(2) 101112 Doi: 10.1177/1010539518824810

https://journals.sagepub.com/home/aph.

[8] Huang, Y., Guo, P., Karmacharya, B. M., Seeruttun, S. R., Xu, D. R., Hao, Y. (2019). Prevalence of hypertension and prehypertension in
Nepal: a systematic review and meta-analysis. Global Health Institute (SGHI), School of Public Health and Institute of National Governance of Sun Yet-sen University. https://ghrp.biomedcentral.com/articles/10.1186/s41 256-019-0102-6.

[9] Nahimana, M., Alypio Nyandwi, A., Muhimpundu, M. A., Olu, O., Condo, J. U., Rusanganwa, A., Koama, J. B., Ngoc, C. T., Gasherebuka, J. B., Ota, M. O., and Okeibunor, J. C. (2018). A population-based national estimate of the prevalence and risk factors associated with hypertension in Rwanda: implications for prevention and control. BMC Public Health 18:2 DOI 10.1186/s12889-017-4536-9.

[10] Wei, Q., Sun, J., Huang, J., Zhou, H. Y., Ding, Y. M., Tao, Y. C., He, S. M., Liu, Y. L., Niu, J. Q. (2015). Prevalence of hypertension and associated risk factors in Dehui City of Jilin Province in China. Macmillan Publishers Limited Journal of Human Hypertension 64-6.

[11]World Health Organization. (2019). Hypertension. https://www.who.int/news-room/factsheets/detail/hypertension.

[12] Adeloye, D., Basquill, C. (2014). Estimating the Prevalence and Awareness Rates of Hypertension in Africa: A Systematic Analysis. Centre for Population Health Sciences, University of Edinburgh Medical School. 9(8): e104300. Doi: 10.1371/journal.pone.0104300. Plos One www.plosone.org. Volume 9, Issue 8 e104300.

[13] Ntulil, S. T., Maimela, E., Alberts, M., Choma, S., Dikotope, S. (2015). Prevalence and associated risk factors of hypertension amongst adults in a rural community of Limpopo Province, South Africa. Department of Public Health, University of Limpopo, Polokwane Campus, South Africa. http://www.phcfm.org.doi:10.4102/phcfm. v7i1.847. [14] Guwatudde1， D., Nankya-Mutyoba， J., Kalyesubula, R., Laurence, C., Adebamowo, C., Ajayi, I. O., Bajunirwe, F., Njelekela, M., Chiwanga, F. S., Reid, T., Volmink, J., Adami, H., Michelle D. Holmes, M. D., Dalal, S. (2015). The burden of hypertension in sub-Saharan Africa: a four-country cross-sectional study. Makerere University College of Health Sci. 
[15] Campbell, N. R. C., Lemogoum, D. (2015). Hypertension in sub-Saharan Africa: a massive and increasing health disaster are awaiting solution. Cardiovascular Journal of Africa. Volume 26, No 4, CDC Principles of Epidemiology in Public Health Practice, Third Edition. An Introduction to Applied Epidemiology and Biostatistics Lesson 3, Section 2: Morbidity Frequency Measures retrieved from, https://www.cdc.gov/csels//ss1978/lesson3/section2. html. On 26 May 2021 at 1735 hours.

[16] Addo, J., Smeeth, L., Leon, D. A. (2007). Hypertension in Sub-Saharan Africa: A Systematic Review. Doi:10.1161/Hypertensionaha.107.093336. [17] Dzudie, A., Rayner, B., Ojji, D., Schutte, A. E., Twagirumukiza, M., Damasceno, A., Ba, S. A., Kane, A., (2017). Roadmap to Achieve 25\% Hypertension Control in Africa by 2025 on behalf of the Pascar task force on hypertension. Cardiovascular Journal of Africa Volume 28, No 4, 262. Doi: 10.5830/CVJA2017-040

[18] Mills, K. T., Bundy, J. D., Kelly, T. N., Reed, J. E., Kearney, P. M., Reynolds, K., Chen, J., He, J. (2016). Disparities of Hypertension Prevalence and Control: A Systematic Analysis of Population-based Studies from 90 Countries. Department of Epidemiology, Tulane University School of Public Health and Tropical Medicine 134:441-450. DOI: 10.1161/Circulationaha.115.018912.

[19] Yan, L. D., Chi, B. H., Sindano, N., Bosomprah, S., Stringer, J. S. A., Chilengi, R. (2015). Prevalence of hypertension and its treatment among adults presenting to primary health clinics in rural Zambia: analysis of an observational database. BMC Public Health 15:933 DOI 10.1186/s12889-015-2258-4.

[20] Goma, F. M., Mwewa, B., Tembo, G. K., Kachamba, M., Syatalimi, C. (2019). May Measurement Month 2017: Blood pressure screening results from Zambia-Sub-Saharan Africa. https://academic.oup.com/eurheartjsupp/articleabstract/21/Supplement.

[21] Rush, K. L., Goma, F. M., Barker, J. A., Olivier, R. A., Ferrier, M. S., Singini, D. (2018). Hypertension prevalence and risk factors in rural and urban Zambian adults in the western province: a crosssectional study. The Pan African Medical Journal -
ISSN: $\quad 1937-\quad 8688 \quad$ www.panafrican-medjournal.com.

[22] Oelke, N., Rush, K., Goma, F., Barker, J., Marck, P., Pedersen, C. (2015). Understanding Perceptions and Practices for Zambian Adults in Western Province at Risk for Hypertension: An Exploratory Descriptive Study. VL - 8. DO - 10.5539/gjhs. v8n2p248 - 259. Global journal of health science.

[23] Mulenga, D., Siziya, S., Rudatsikira, E., Mukonka, V. M., Babaniyi, O., Songolo, P., Muula, A. (2013). District specific correlates for hypertension in Kaoma and Kasama rural districts of Zambia. Rural and Remote Health 2013; 13: 2345. https://doi.org/10.22605/RRH2345.

[24] Arries, E. J., Maposa, S. (2013). Cardiovascular Risk Factors Among Prisoners: An Integrative Review Volume 9. www.journalforensinursing.com. [25] Porter, L. C. (2014). Incarceration and Postrelease Health Behavior. Journal of Health and Social Behavior Doi: 10.1177/0022146514531438 201455 Department of Sociology Kent State University Kent, https://www.researchgate.net/publication/262695433. [26] Houle, B. (2014). The Effect of Incarceration on Adult Male BMI Trajectories, United States, 19812006. March; 1(1): 21-28. Doi: 10.1007/s40615-0130003-1. NIH-P. Institute of Behavioral Science, University of Colorado.

[27]Mokoko, P. (2018). Health Literacy for Hypertension in the Inmate Population. Walden Dissertations and Doctoral Studies Walden University. Doctoral Studies Collection. https://scholarworks.waldenu.edu/cgi/viewcontent.c gi article $=6253 \&$ context $=$ dissertati.

[28]Han, H., Chan, K., Song, H., Nguyen, T., Lee, J., T. Kim, M. T. (2011). Development and Evaluation of a Hypertension Knowledge Test for Korean Hypertensive Patients. J Clin Hypertens (Greenwich). 2011; 13(10):750-757. doi:10.1111/j.17517176.2011.00497. x.

[29] Timnou, A. T., Boombhi, J., Njonnou, S. R. S., Jingi, A. M., Efon, K. N., Bâ, H., Mfeukeu-Kuate, L., Nganou-Ngnindjo, C. N., Amougou, S. N., Essomba, M. N., Kebiwo, O. K., Ndjonya, S. T., Mayap, V. P., Menanga, A. P., Kingue, S. (2019). Prevalence of hypertension and associated risk factors among a group of prisoners in Yaoundé Central Prison: a 
cross-sectional study. Journal of Xiangya Medicine. University of Yaoundé http://dx.doi.org/10.21037/jxym.2019.05.01.

[30] Gambhir, S. (2018). Prevalence of Hypertension among Incarcerated Males of Jhumka Regional Prison, Eastern Nepal. Journal of Hypertension: Volume 36 - Issue - p e345 doi: 10.1097/01.hjh.0000549409.97583.00.

[31] Yamane, Taro. (1967). Statistics: An Introductory Analysis, 2nd Edition, New York: Harper and Row.

[32] Umbach, R., Raine, A., Leonard, N. R. (2017). Cognitive Decline as a Result of incarceration and the effects of a CBT/MT intervention. A ClusterRandomized Controlled trial. Criminal Justice and Behavior, 2018, Vol. 45, No. 1, January 2018, 31 55. DOI: 10.1177/0093854817736345. 2017 International Association for Correctional and Forensic Psychology.

[33] Sanne, S., Muntner, P., Kawasaki, L., Hyre, A., Desalvo, K. B. 2008. Hypertension Knowledge among Patients from an Urban Clinic. Ethnicity \& Disease, Volume 18. Ethn Dis. 2008; 18(1):42-47. https://pubmed.ncbi.nlm.nih.gov/18447098. 